\title{
Unbalance and Harmonic Mitigation Using Battery Inverters
}

\author{
Ling Xu, Student Member, IEEE, Zhixin Miao, Senior Member, IEEE, Lingling Fan, Senior Member, IEEE, \\ and Geroge Gurlaskie
}

\begin{abstract}
Slight unbalance in voltage in a distribution system can result in high unbalance in currents due to induction machine loads. Further, a wide spectrum of harmonic components will be generated in currents due to uncontrolled power electronic loads employing diode-bridge rectifiers. Power quality becomes a critical issue for a microgrid if both induction machine loads and rectifier loads exist. Mitigation of unbalanced and harmonic currents without additional investments is of interest of utility companies. With energy storage systems such as batteries installed for peak shaping and valley filling, power quality improvement through voltage source converter (VSC) based battery inverters is proposed in this paper. This paper develops a Unbalanced Current (UC) and Harmonic Current (HC) controller for battery inverters based on the structure of Proportional-Resonance (PR) controller. Real-Time simulations carried out in RT-LAB demonstrate the grid current can be successfully improved to meet the IEEE standard when the negative sequence component of grid voltage is lower than $4 \%$ for the study system in this paper.
\end{abstract}

Index Terms-Unbalance, harmonics, Proportional-Resonance (PR), Voltage Source Converter, Battery.

\section{INTRODUCTION}

$\mathbf{M}$ ICROGRID is a promising technology to integrate distributed energy resources (DERs) [1-[3] such as wind turbines and solar photovoltaic panels. A common characteristic of those renewable energy resources is the intermittency on power output. Therefore, in order to compensate the intermittency and improve the power output profile, energy storage devices are always required such as batteries [4-6].

Induction motor loads in a microgrid occupy a large portion of loads. Such loads are vulnerable to grid voltage unbalance. [7, 8] demonstrate the effect of voltage unbalance. For high power induction machine, even very low level of grid voltage unbalance may lead to very high percentage of unbalanced currents if the slip is small [9]. In order to prevent unbalanced currents flowing into a utility grid, [10-12] proposed to use a shunt connected Voltage Source Converter (VSC) to inject compensation currents with controllers designed in a $d q$ synchronous frame. Other than compensating unbalanced currents, STATCOM and D-STATCOM have been widely used to compensate the unbalanced voltage at the Point of Common Coupling (PCC) [13-18].

Unbalance in grid voltage can also cause low order harmonic currents due to power electronic interfaced loads. In [9], an example case study shows that a diode rectifier electric

L. Xu, Z. Miao, and L. Fan are with Department of Electrical Engineering at University of South Florida, Tampa FL (Email: linglingfan@usf.edu). George Gurlaskie is with Duke Energy Florida. drive causes increase in 3rd harmonics due to unbalanced grid voltage. Active filter is a solution to mitigate the harmonic currents [19,-22]. The current control strategies (linear current control, digital deadbeat control, and hysteresis control) are discussed and compared in [23]. In the linear current control scheme, multiple $d q$ rotating frames are utilized to convert harmonic and negative sequence current components to dc variables. Proportional-integral (PI) controllers, effective for dc variable controls, are then applied to regulate currents. An alternative control scheme developed in [24, 25] is called Proportional-Resonant (PR) controller. PR controllers can regulate sinusoidal signals. With PR control, the complexity of harmonic current control system can be reduced.

Unbalanced and harmonic current mitigation needs the installation of VSCs, such as active filters. For microgrids equipped with energy storage systems such as VSC interfaced batteries, the batteries can be used not only for peak shaping but also for power quality improvement.

The objective of this paper is to explore battery inverters' capability in power quality improvement, specifically in unbalance and harmonic current mitigation. A control strategy for the inverter of a battery will be developed to compensate unbalanced and harmonic currents under various grid voltage conditions. In the sections following, the paper first describes the system configuration of a microgrid with a battery, a PV station, an induction machine load and a rectifier interfaced load. In Section III, the mechanism and the block diagram of the controller based on PR control scheme are presented. Results of real-time digital simulation carried out in RT-LAB are presented in Section IV. Section V concludes the paper.

\section{SYSTEM CONFIGURATION}

The microgrid studied for this paper consists of a PV station and a battery as the distribution generation and storage devices respectively. An induction machine and a diode rectifier interfaced RL load are chosen as the customer loads. The microgrid is connected with the main grid via a transformer. Fig. 1] shows the topology of the study system. The parameters are listed in Table [1 The battery system consists of two groups connected in series. Each group has an equivalent open circuit dc voltage at $4.1 \mathrm{kV}$. The maximum active power capability of which is $1 \mathrm{MW}$ for each group, and the energy capacity is $1 \mathrm{MWh}$, which means the whole battery station could inject 2 MW active power to the microgrid for 1 hour.

The PV array consisted of many small PV panels, which could build up an open circuit dc voltage to $2 \mathrm{kV}$ for the whole 
array. The short circuit dc current under nominal insolation level is set to $1 \mathrm{kA}$. The PV array is connected to a dc/dc converter, which is controlled by Maximum Power Point Tracking (MPPT) algorithm. A dc/ac inverter which utilizes IGBTs connects the dc/dc converter to the microgrid.

The induction machine is used to simulate traditional customer load. A simple RL load connected with a rectifier is a representation of uncontrollable rectifier interfaced loads.

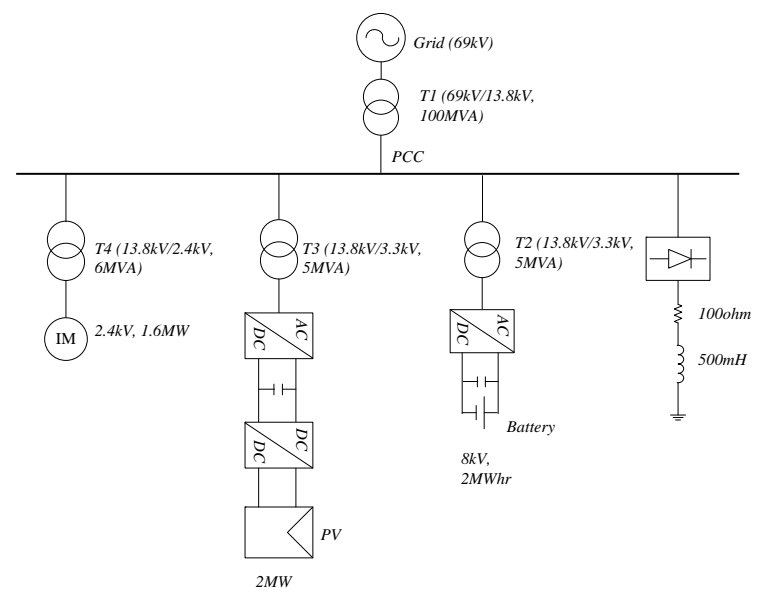

Fig. 1. System topology of a microgrid.

TABLE I

Simulation System Parameters

\begin{tabular}{c|c}
\hline \hline Quantity & Value \\
\hline \hline ac grid voltage & $69 \mathrm{kV}$ (L-L RMS) \\
\hline Transformer 1 & $69 \mathrm{kV} / 13.8 \mathrm{kV}, 100 \mathrm{MVA}$, leakage $8 \% \mathrm{pu}$ \\
\hline Transformer 2 & $13.8 \mathrm{kV} / 3.3 \mathrm{kV}, 5 \mathrm{MVA}$, leakage 10\%pu \\
\hline Transformer 3 & $13.8 \mathrm{kV} / 3.3 \mathrm{kV}, 5 \mathrm{MVA}$, leakage 10\%pu \\
\hline Transformer 4 & $13.8 \mathrm{kV} / 2.4 \mathrm{kV}, 6 \mathrm{MVA}$, leakage $10 \% \mathrm{pu}$ \\
\hline Induction machine ratings & $2.4 \mathrm{kV}, 1.6 \mathrm{MW}$ \\
\hline Battery ratings & $8.2 \mathrm{kV}, 2 \mathrm{MWhr}$ \\
\hline PV ratings & $2 \mathrm{kV}, 2 \mathrm{MVA}$ \\
\hline Load ratings & $100 \mathrm{ohm}+500 \mathrm{mH}$ \\
\hline \hline
\end{tabular}

\section{A. Consequence of unbalance in motor loads}

The positive and negative sequence currents can be written as (1) and (2).

$$
\begin{aligned}
& I_{p s}=\frac{V_{p}}{\sqrt{\left(R_{s}+\frac{R_{r}}{s}\right)^{2}+\left(X_{l s}+X_{l r}\right)^{2}}} \\
& I_{n s}=\frac{V_{n}}{\sqrt{\left(R_{s}+\frac{R_{r}}{2-s}\right)^{2}+\left(X_{l s}+X_{l r} r\right)^{2}}}
\end{aligned}
$$

where $R_{s}$ and $X_{l s}$ are stator resistance and leakage reactance respectively, $R_{r}$ and $X_{l r}$ are rotor resistance and leakage reactance referred to stator side respectively. $X_{m}$ is the magnetizing reactance. $V_{p}$ and $V_{n}$ represent the positive and negative sequences of voltage, while $I_{p s}, I_{p r}$ and $I_{n s}, I_{n r}$ are the corresponding currents. For example, if $R_{s}=0.3, R_{r}=0.1$, $X_{l s}=0.5, X_{l r}=0.2, s=0.01, V_{p}=1.0$, and $V_{n}$ is only $2 \%$ of $V_{p}$, the resulting negative sequence current is $I_{n s}=0.0256$, whereas, the positive sequence current is $I_{p s}=0.0969$. The negative sequence current is $26.42 \%$ of positive sequence current although the negative sequence voltage is only $2 \%$. Therefore, when there is a small percentage of unbalance in the PCC voltage, the induction machine will inject significant unbalanced currents to the system.

The consequence of unbalanced voltage applied in motor loads is demonstrated in Fig. 2, which shows the induction machine currents. The system voltage contains a $2 \%$ negative sequence. The unbalance degree in current reaches $26 \%$. Such high magnitude negative sequence currents may cause severe problems to the end users, since it may cause vibrations on the machine torque, unstable rotating speed and noise. The power factor and efficiency of machine may get worsen as well. The worst case would be shut down of the machine. For sensitive industry customers, such system performance is not acceptable.

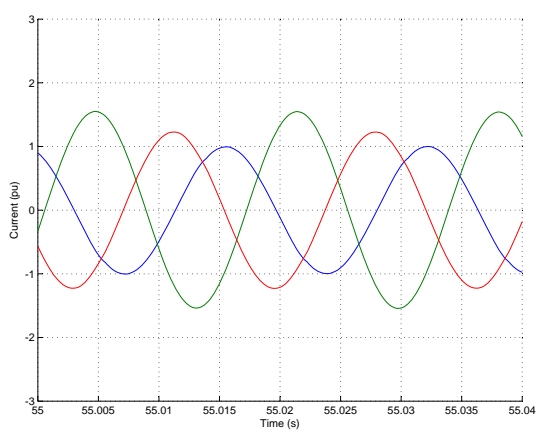

Fig. 2. Induction machine current under $2 \%$ unbalanced grid voltage.

\section{B. Consequence of unbalance in rectifier loads}

For a diode rectifier, if the ac side is subject to unbalance, the instantaneous power will contain a dc component and a harmonic of double line frequency. Ignore the switching loss, this instantaneous power equals the dc side instantaneous power. Therefore, the dc current will contain second harmonic component. At ac side, there will be a 3rd harmonics.

The consequence of unbalanced voltage applied in rectifier loads is presented in Fig. 3. The system voltage has $2 \%$ negative sequence component. The rectifier phase A current is presented in Fig. 3 Under balanced grid voltage, the main harmonic components in currents are 5th and 7 th order. At the unbalance case, the largest harmonic shifts to 3rd order as shown in in Fig. 3. The grid current injected into main grid is critical to power quality. The current harmonics limits for a power system can be found in IEEE standard [26], which is $4 \%$ for harmonic order of 9 and less, and $2 \%$ for harmonic order of 15 and less. Fig. 5 depicts the FFT analysis of grid current under $2 \%$ unbalanced grid voltage. The red bar is the magnitude percentage corresponding to fundamental current for various odd harmonic orders, while the green bar is the limit specified by the standard for different odd harmonic order currents. Based on the system parameters and short circuit calculation, the THD limit of grid current for the model is $8 \%$ [26]. However, the actual THD of the current for this case is $15.86 \%$, which is almost 2 times of the limit. 


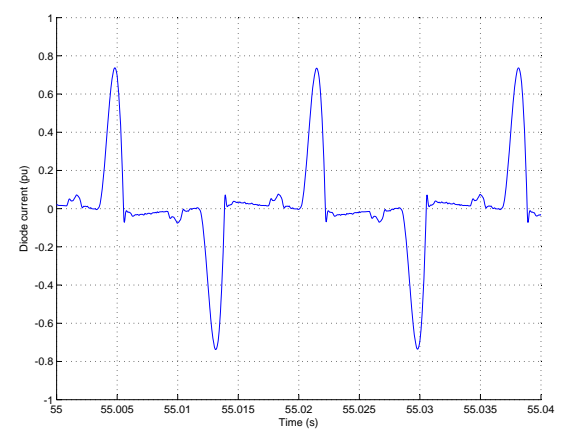

Fig. 3. Rectifier current under $2 \%$ unbalanced grid voltage.

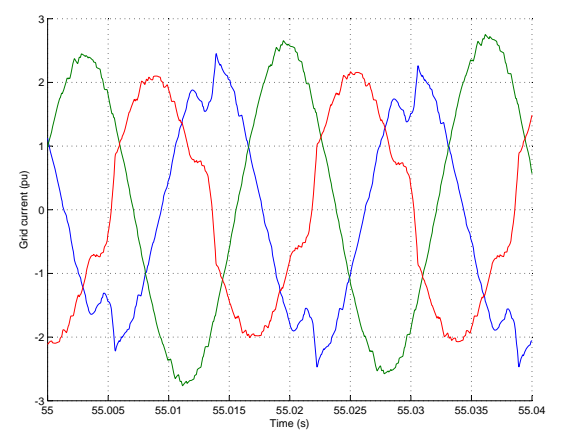

Fig. 4. Grid current under $2 \%$ unbalanced grid voltage.

\section{Controller Design}

Since the battery is connected with the microgrid via a VSC, it is possible to design a proper control strategy to have the VSC to compensate both negative sequence and harmonic currents injected into the grid. The reason that we do not use the PV's VSC to perform the compensation is that the VSC of PV has to control the dc voltage for the PV panel's dc/dc converter. The battery has a relatively stable dc voltage. So its VSC has more freedom to implement sophisticated controls.

In Fig. 6 the microgrid is simplified with each component's current labeled. Since the major negative sequence and harmonic currents are contributed by induction machine and rectifier, the PV station is ignored in Fig. 66 Assuming the PCC voltage is unbalanced, the induction machine current $i_{m}$ can

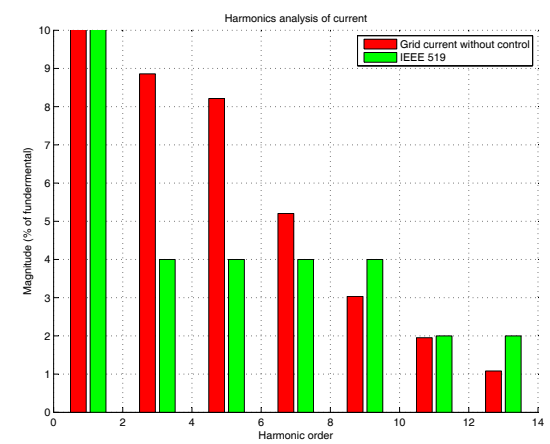

Fig. 5. FFT analysis of grid current under $2 \%$ unbalanced grid voltage. be written as $i_{m}=i_{m p}+i_{m n}$, where $i_{m p}$ and $i_{m n}$ represent the positive and negative sequence current. The rectifier load current $i_{r}$ also can be written as $i_{r}=\sum_{k=1}\left(i_{r p \_k}+i_{r n \_}\right)$, where $k=1,2,3 \ldots$ is the harmonic order and the subscript $r p$ and $r n$ represent positive and negative sequences. Apparently, the current $i_{g}$ injected into the grid would contain various harmonic currents and negative sequences, which is not acceptable in terms of power quality.

One solution for this problem is to design a proper control strategy for the battery's VSC and make it inject specific currents to the grid for compensation. For instance, let the battery $i_{b}=i_{b 0}-i_{m n}-\sum_{k=2} i_{r p_{-} k}-\sum_{k=1} i_{r n \_}$, where $i_{b 0}$ is the battery's own current order. So the total grid current $i_{g}$ will only have positive sequence and the negative sequence and harmonic currents will be canceled out.

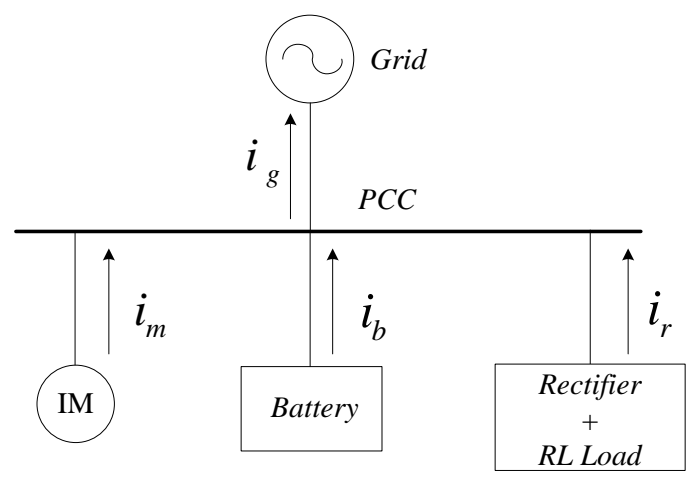

Fig. 6. Simplified system topology.

The conventional control scheme for VSC is $d q$ decoupled control algorithm, which is shown in Fig. 7. $\theta$ is the system voltage angle at nominal frequency of $60 \mathrm{~Hz}$. For a balanced system, the currents $i_{d}$ and $i_{q}$ are both dc quantities, and the PI controllers are able to regulate them in order to track the respective references. However, under unbalanced case, the $d q$ currents are no longer dc quantities but contain ac time varying currents at frequency of $120 \mathrm{~Hz}$. Since PI controllers can not track ac signals, two low pass filters are needed to get rid of the $120 \mathrm{~Hz}$ components. Similarly, in order to control the negative sequence current, a negative sequence $d q$ transformation is needed and two low pass filters are required to filter out the $120 \mathrm{~Hz}$ positive sequence part. Moreover, this control structure is specific for nominal frequency, for each harmonic order, a complete set of the controller shown in Fig. 7 is needed. The difference is the angle $\theta$ will be the corresponding angle at each harmonic order. Obviously, the complexity of the overall controller is very high and the calculation burden will cost much resources for a real controller.

Instead of the conventional $d q$ controller, a ProportionalResonance (PR) controller is more suitable for such kind of application. The transfer function of a PR controller is shown in (3), where $K_{p}$ is the proportional gain and $K_{i h}$ is the resonance gain for each harmonic order. The control structure is also shown in Fig. 8, where only first order and second order controller are drawn. The current regulated by PR controller has to be ac current as it has very limited 


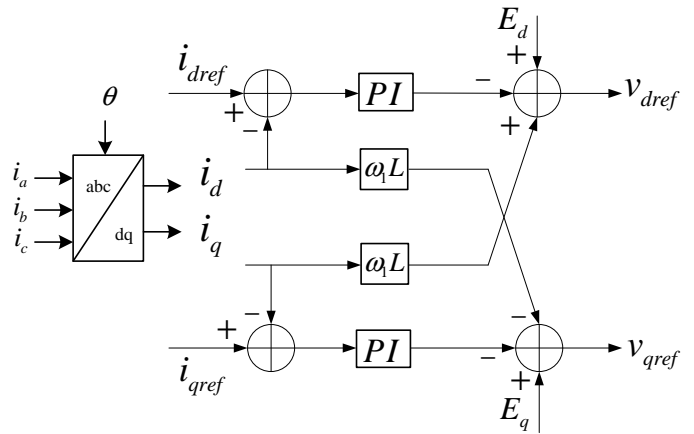

Fig. 7. Conventional dq control strategy for VSC.

response for dc signals. Another advantage of PR controller is for each order of current, the controller can regulate both positive and negative sequence as long as the frequency is the same with the controller's harmonic order [27, 28]. Hence, the overall controller would be much more easier to implement. Since the controller needs ac current signals, instead of $d q$ transformation, the $a b c$ currents will be transformed into $\alpha \beta$ frame. The current reference of the battery shown above will also be transformed into $\alpha \beta$. Obviously, in order to get a proper current reference for battery, a signal conditioning unit which can correctly extract the negative sequence and harmonic currents of $i_{m}$ and $i_{r}$ is needed.

$$
G_{h}(s)=K_{p}+\sum_{h=2,3,4 \ldots} K_{i h} \frac{s}{s^{2}+(\omega \cdot h)^{2}}
$$

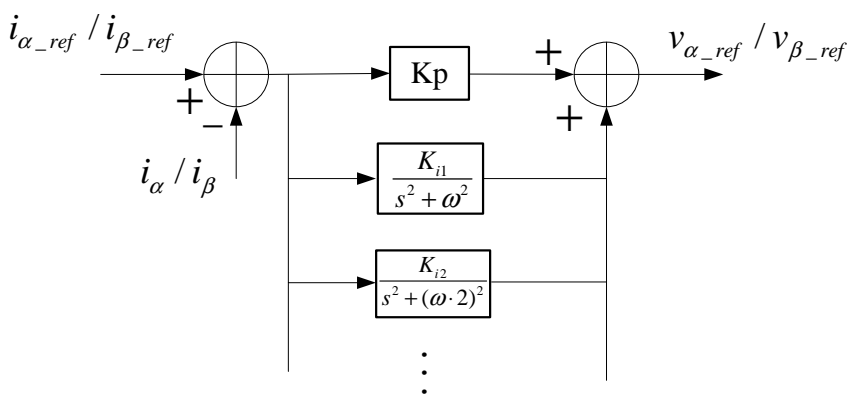

Fig. 8. A PR controller structure.

In order to extract the negative sequence and harmonic order components of induction machine and rectifier currents, one method is to obtain the positive sequence component and subtracted from the total current. Fig. 9 depicts the signal conditioning block to extract the negative and harmonic currents components. For example, the three-phase induction machine currents $i_{m_{-} a}, i_{m_{-} b}$, and $i_{m_{-} c}$ are sent to a $a b c / d q$ transformation block at fundamental frequency to calculate the currents in $d q$ frame, which are $i_{m_{-} d}^{+-\sim}$ and $i_{m_{-} q}^{+-}$respectively. The subscripts,+- , and $\sim$ represent positive, negative and harmonic components respectively. Since the currents are measured under unbalanced voltage, the negative sequence current may have a relatively high magnitude. A notch filter tuned at $120 \mathrm{~Hz}$ is used to filter out the negative sequence current, which is a $120 \mathrm{~Hz}$ ac signal in $d q$ frame. The harmonic currents in $d q$ frame are at even higher harmonic order frequencies, for instance, the 3rd harmonic order current in $d q$ frame would be $120 \mathrm{~Hz}$ and $240 \mathrm{~Hz}$ ac signals. Therefore, a low pass filter (LPF) is used to get rid of the harmonic components. After that, the $d q$ currents contain only positive sequence which are transformed back to $a b c$ quantities and subtracted from the total $a b c$ currents. After the substraction, the currents contain only negative sequence and harmonic order components. A $a b c / \alpha \beta$ block will turn the current signals into $\alpha \beta$ frame and will be used by the controllers shown in Fig. 8

The controller parameters are listed in Table ??, and the respective bandwidth for each harmonic order controller is shown in Table ?? with 1st, 3rd and 5th order controller listed.

\section{VALIDATION}

A simulation model of microgrid is built in RT-LAB in order to validate the capability of the battery inverter for negative sequence and harmonics current compensation. RT-LAB is a Real-Time Digital Simulator manufactured by OPAL-RT which can simulate the power system model with detailed power electrotonic switches in real-time. Therefore, it can provide precise simulation results and take the switching details of IGBTs into account. Moreover, the simulation can run in real time and highly improve simulation efficiency. Fig. ?? shows the setup of RT-Lab simulator and its corresponding oscilloscopes which monitor the simulation signals, such as voltage, current and power.

A three-phase programmable voltage source is selected to emulate the grid. Besides the regular positive sequence voltages, the programmable voltage source can also generate negative sequence voltages and superimpose them onto the positive sequence voltage. Therefore, that feature can be used to simulate the unbalanced voltage cases. Three case studies will be conducted to investigate the current compensation capability of the battery inverter with PR controller under different level of grid voltage unbalance.

\section{A. Case I}

The microgrid built in RT-LAB consists of five main components: the main grid, an induction machine, a rectifier interfaced load, a battery and a PV station. The electrical parameters are listed in Table 1 .

The first case investigates the system performance while the UC controller is enabled. The HC controller is firstly disabled and then enabled to validate the harmonic current compensation capability by battery inverter. The negative sequence of grid voltage is set to $0.5 \%$, which indicates a relatively low unbalanced grid voltage case. Fig. 10 (a) shows the induction machine currents which contain $7 \%$ negative sequence component, and Fig. 10 (b) shows the grid currents with both UC and $\mathrm{HC}$ controllers enabled. Fig. 11 shows the rectifier phase A current, which has various harmonic components. The 3rd harmonic current is smaller comparing with Fig. 2. Generally, the 3rd harmonic current increase as the voltage contains more negative sequence. 


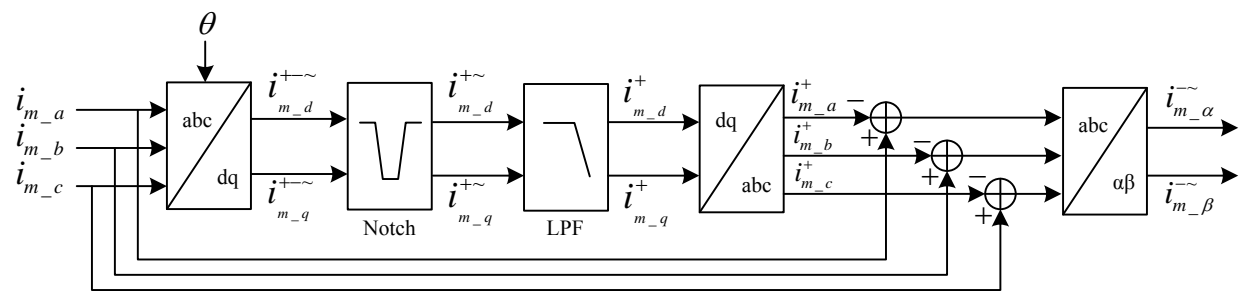

Fig. 9. Signal conditioning.
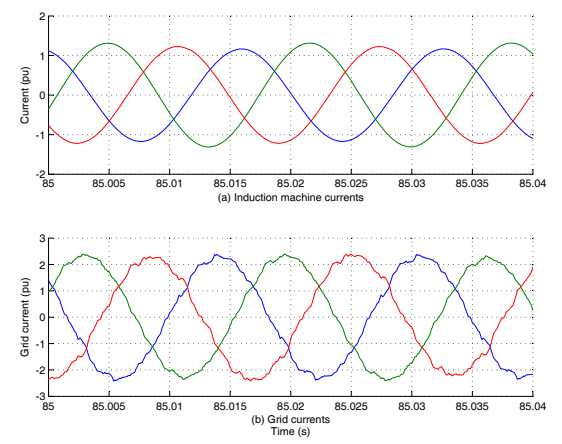

Fig. 10. Induction machine and grid currents under $0.5 \%$ unbalanced grid voltage.

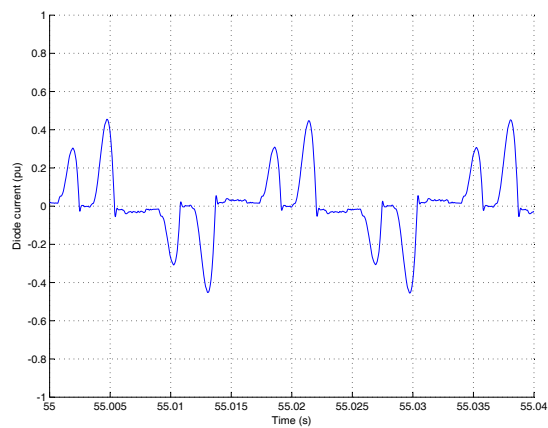

Fig. 11. Rectifier current under $0.5 \%$ unbalanced grid voltage.

Fig. 12 depicts the battery inverter current in stationary frame. The blue trace is the battery inverter $\alpha$ current reference and the red line is the actual $\alpha$ current. Since the battery has to inject harmonic currents to compensate the rectifier current, the reference current is already distorted. Thanks to the UC and $\mathrm{HC}$ controllers, the actual current tracks the reference in a precisely manner both on $\alpha$ and $\beta$ axes. Therefore, the grid phase A current shown in Fig. 13 (b) is improved comparing to Fig. 13 (a) when the HC controller is disabled. The FFT analysis of Case I is included in Fig. 14. Grid current with and without controller enabled are compared with. The 5th and 11th order harmonic current are beyond the limits set by [26] when the HC controller is disabled. With the help of $\mathrm{HC}$ controller, all odd order harmonic currents are less than the limits. The THD of grid current without HC controller is $11.3 \%$ while the THD of grid current decreases to $5.1 \%$ with HC controller enabled.

Due to the page limits, the two other case studies are not
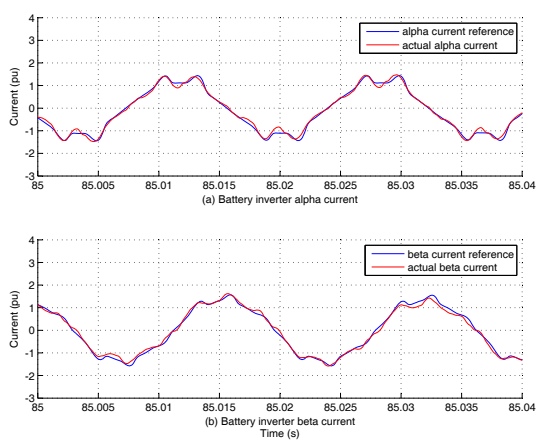

Fig. 12. Battery inverter currents in the stationary frame, $i_{b \alpha}$ and $i_{b \beta}$.
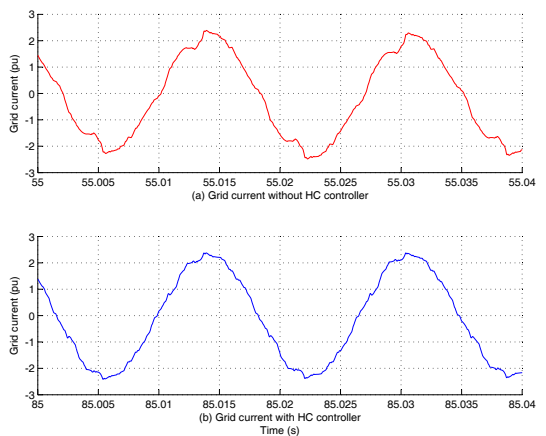

Fig. 13. Grid current under $0.5 \%$ unbalanced grid voltage, without and with controller.

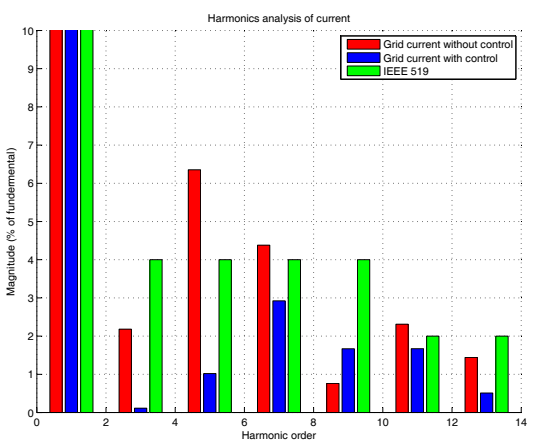

Fig. 14. FFT analysis of grid current under $0.5 \%$ unbalanced grid voltage. 
presented in this paper. A longer version of this paper is posted at

http: //power.eng.usf.edu.

\section{CONClusion}

Slight voltage unbalance can lead to high degree of unbalance and harmonics in currents in a microgrid with induction machine and rectifier loads. This paper explores the capability of a battery's inverter in power quality improvement. A PR controller is designed to mitigate unbalanced and harmonic currents. The controller is tested under different level of grid voltage unbalance. The case studied in RT-LAB shows the battery inverter can successfully compensate unbalanced and odd harmonic currents when the grid voltage has $0.5 \%$ and $2 \%$ negative sequence component. The THD level and profile of harmonic currents meet the requirement of corresponding IEEE standard. However, when the negative sequence component increases to $4 \%$, the 3rd and 5th harmonic currents slightly exceed the limit. This phenomenon implies the battery inverter can improve the grid current profile at the PCC without any additional investment. However, it may need additional solution in order to improve the current distortion if the grid voltage contains high level of unbalanced component.

\section{APPENDIX A}

Controller parameters:

$K_{p}=0.02, K_{i h}=500$.

Controller bandwidth:

1st order harmonics: $1.036 \mathrm{~Hz}$

3rd order harmonics: $2.914 \mathrm{~Hz}$

5th order harmonics: $4.713 \mathrm{~Hz}$.

\section{ACKNOWLEDGEMENT}

This research is supported in part by Duke Energy through Community Power Systems Simulation Project.

\section{REFERENCES}

[1] R. Lasseter and P. Paigi, "Microgrid: a conceptual solution," in Power Electronics Specialists Conference, 2004. PESC 04. 2004 IEEE 35th Annual, vol. 6, june 2004, pp. 4285 - 4290 Vol.6.

[2] F. Peng, Y. W. Li, and L. Tolbert, "Control and protection of power electronics interfaced distributed generation systems in a customerdriven microgrid," in Power Energy Society General Meeting, 2009. PES '09. IEEE, july 2009 , pp. $1-8$.

[3] N. Hatziargyriou, "microgrids [guest editorial]," Power and Energy Magazine, IEEE, vol. 6, no. 3, pp. 26 -29, may-june 2008.

[4] S. Teleke, M. Baran, A. Huang, S. Bhattacharya, and L. Anderson, "Control strategies for battery energy storage for wind farm dispatching," Energy Conversion, IEEE Transactions on, vol. 24, no. 3, pp. 725 -732, sept. 2009.

[5] M. Bragard, N. Soltau, S. Thomas, and R. De Doncker, "The balance of renewable sources and user demands in grids: Power electronics for modular battery energy storage systems," Power Electronics, IEEE Transactions on, vol. 25, no. 12, pp. 3049 -3056, dec. 2010.

[6] S. Vazquez, S. Lukic, E. Galvan, L. Franquelo, and J. Carrasco, "Energy storage systems for transport and grid applications," Industrial Electronics, IEEE Transactions on, vol. 57, no. 12, pp. 3881 -3895, dec. 2010.

[7] Y.-J. Wang, "Analysis of effects of three-phase voltage unbalance on induction motors with emphasis on the angle of the complex voltage unbalance factor," Energy Conversion, IEEE Transactions on, vol. 16, no. 3, pp. 270-275, 2001

[8] P. Pillay, P. Hofmann, and M. Manyage, "Derating of induction motors operating with a combination of unbalanced voltages and over or undervoltages," Energy Conversion, IEEE Transactions on, vol. 17, no. 4, pp. 485-491, 2002.

[9] A. von Jouanne and B. Banerjee, "Assessment of voltage unbalance," Power Delivery, IEEE Transactions on, vol. 16, no. 4, pp. 782-790, 2001.

[10] Y. W. Li, D. Vilathgamuwa, and P. C. Loh, "A grid-interfacing power quality compensator for three-phase three-wire microgrid applications," Power Electronics, IEEE Transactions on, vol. 21, no. 4, pp. 1021-1031, 2006.

[11] Y. Li, D. Vilathgamuwa, and P. C. Loh, "Microgrid power quality enhancement using a three-phase four-wire grid-interfacing compensator," Industry Applications, IEEE Transactions on, vol. 41, no. 6, pp. 17071719, 2005.

[12] M. Hojo, Y. Iwase, T. Funabashi, and Y. Ueda, "A method of three-phase balancing in microgrid by photovoltaic generation systems," in Power Electronics and Motion Control Conference, 2008. EPE-PEMC 2008. 13th, 2008, pp. 2487-2491.

[13] C. Hochgraf and R. Lasseter, "Statcom controls for operation with unbalanced voltages," Power Delivery, IEEE Transactions on, vol. 13, no. 2, pp. 538-544, 1998.

[14] B. Blazic and I. Papic, "Improved d-statcom control for operation with unbalanced currents and voltages," Power Delivery, IEEE Transactions on, vol. 21, no. 1, pp. 225-233, 2006.

[15] K. Li, J. Liu, Z. Wang, and B. Wei, "Strategies and operating point optimization of statcom control for voltage unbalance mitigation in three-phase three-wire systems," Power Delivery, IEEE Transactions on, vol. 22, no. 1, pp. 413-422, 2007.

[16] Q. Song and W. Liu, "Control of a cascade statcom with star configuration under unbalanced conditions," Power Electronics, IEEE Transactions on, vol. 24, no. 1, pp. 45-58, 2009.

[17] G. Escobar, A. Stankovic07, and P. Mattavelli, "An adaptive controller in stationary reference frame for d-statcom in unbalanced operation," Industrial Electronics, IEEE Transactions on, vol. 51, no. 2, pp. 401409, 2004.

[18] A. Leon, J. Mauricio, J. Solsona, and A. Gomez-Exposito, "Software sensor-based statcom control under unbalanced conditions," Power Delivery, IEEE Transactions on, vol. 24, no. 3, pp. 1623-1632, 2009.

[19] H. Fujita, T. Yamasaki, and H. Akagi, "A hybrid active filter for damping of harmonic resonance in industrial power systems," Power Electronics, IEEE Transactions on, vol. 15, no. 2, pp. 215-222, 2000.

[20] S. Bhattacharya, T. M. Frank, D. Divan, and B. Banerjee, "Active filter system implementation," Industry Applications Magazine, IEEE, vol. 4, no. 5, pp. 47-63, 1998.

[21] F. Z. Peng, "Application issues of active power filters," Industry Applications Magazine, IEEE, vol. 4, no. 5, pp. 21-30, 1998.

[22] H. Akagi, "New trends in active filters for power conditioning," Industry Applications, IEEE Transactions on, vol. 32, no. 6, pp. 1312-1322, 1996.

[23] S. Buso, L. Malesani, and P. Mattavelli, "Comparison of current control techniques for active filter applications," Industrial Electronics, IEEE Transactions on, vol. 45, no. 5, pp. 722-729, 1998.

[24] L. Fan, R. Kavasseri, H. Yin, C. Zhu, and M. Hu, "Control of dfig for rotor current harmonics elimination," in Power \& Energy Society General Meeting, 2009. PES'09. IEEE. IEEE, 2009, pp. 1-7.

[25] L. Fan, H. Yin, and Z. Miao, "A novel control scheme for dfig-based wind energy systems under unbalanced grid conditions," Electric Power Systems Research, vol. 81, no. 2, pp. 254-262, 2011.

[26] "Ieee recommended practices and requirements for harmonic control in electrical power systems," IEEE Std 519-1992, pp. 1-101, 1993.

[27] F. Blaabjerg, R. Teodorescu, M. Liserre, and A. Timbus, "Overview of control and grid synchronization for distributed power generation systems," Industrial Electronics, IEEE Transactions on, vol. 53, no. 5, pp. 1398-1409, 2006.

[28] R. Teodorescu, F. Blaabjerg, U. Borup, and M. Liserre, "A new control structure for grid-connected $\mathrm{lcl}$ pv inverters with zero steady-state error and selective harmonic compensation," in Applied Power Electronics Conference and Exposition, 2004. APEC '04. Nineteenth Annual IEEE, vol. 1, 2004, pp. 580-586 Vol.1. 